\title{
Experiência de ensino na área de Geoquímica Ambiental em um programa de Pós-Graduação em Geociências
}

\author{
Teaching experience in the area of Environmental Geochemistry in a Graduate Program in Geosclences
}

\author{
Katia Noriko Suzuki ${ }^{1}$, Patricia Alexandre de Souza ${ }^{1,2}$,Rose Mary Latinl ${ }^{3}$, Ana Paula de Castro Rodrigues ${ }^{1,4}$ \\ 1 - Universidade Federal Fluminense, Programa de Pós-Graduação em Geociências (Geoquímica), Niteról, RJ. \\ 2 - Universidade Federal do Tocantins, Curso de Engenharia Florestal, Campus de Gurupi, Gurupi, TO. \\ 3 - Universidade Federal Fluminense, Programa de Pós-Graduação em Ensino de Clências da Natureza e Departamento de Físico-Química, Niteról, RJ. \\ 4 - Universidade Federal do Rio de Janeiro, Instituto de Biologia, Departamento de Biologia Marinha, Centro de Ciências da Saúde, Rio de Janeiro, RJ.

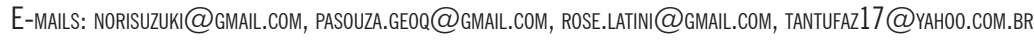

\begin{abstract}
This work consists of a report on the experience of teaching an interdisciplinary discipline in the field of environmental geochemistry. The course was designed by three post-doctoral students from the Post-graduate Program in Geosciences at the Universidade Federal Fluminense, offered as an elective course for masters and doctoral students in the second period of 2016. The contents were covered in three disciplinary modules, which involved field and laboratory activities. The performance of students was analyzed based on theoretical and practical classes, whereas the discipline and documents were obtained through questionnaires to students. In general, the students presented excellent performance, and considered that the approach of the discipline with field and laboratory activities were objects that facilitate learning. They considered that the contents taught in modules were motivating and the field and laboratory activities as objects that facilitate learning. They also highlighted the importance of these practices in the development of an integrating vision of Environmental Geochemistry.
\end{abstract}

Resumo: Este trabalho descreve e analisa a experiência de oferecimento de uma disciplina de caráter interdisciplinar na área da Geoquímica Ambiental, elaborada e ministrada por três pós-doutoras do programa de Pós-graduação em Geociências da Universidade Federal Fluminense e, ofertada como disciplina eletiva para mestrandos e doutorandos, no segundo período de 2016. Os conteúdos foram abordados em três módulos disciplinares, os quais envolveram atividades de campo e de laboratório. 0 desempenho dos discentes foi analisado com base nas aulas teóricas e práticas, enquanto, a disciplina e os docentes foram avaliados através de questionários aplicados aos discentes. Em geral, os discentes apresentaram ótimo desempenho, e consideraram que os conteúdos ministrados em módulos foram motivadores e, as atividades de campo e laboratoriais, como objetos facilitadores do aprendizado. Eles ainda destacaram a importância das práticas no desenvolvimento de uma visão integradora da Geoquímica Ambiental.
Citation/Citação: Suzuki, K. N., Souza, P. A. de, Latini, R. M. \& Rodrigues, A. P. C. (2020). Experiência de ensino na área de Geoquímica Ambiental em um Programa de Pós-Graduação em Geociências. Terræ Didatica, 16, 1-12, e020048. doi: 10.20396/ td.v16i0.8660905.

Keywords: Earth Sciences, Teaching Practices, Didactic Resources, Interdisciplinarity.

Palavras-chave: Ciências da Terra, Práticas de Ensino, Recursos Didáticos, Interdisciplinaridade.

\section{Manuscript/Manuscrito:}

Received/Recebido: 17/08/2020

Revised/Corrigido: 24/09/2020

Accepted/Aceito: 24/11/2020

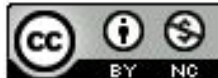

\section{Introdução}

As Geociências ou Ciências da Terra são formadas por especialidades científicas que estudam a composição, estrutura e processos dinâmicos do nosso planeta ao longo de sua história, em especial, aqueles que se manifestam na superfície (processos supergênicos). A Geoquímica, por sua vez, iniciada pelo químico suíço-norueguês Goldschmidt na década de 1930, é um campo das Geociências que se baseia nos princípios da química e da física para explicar os mecanismos que regulam o funcionamento no passado e no presente, dos principais sistemas geológicos (manto, crosta, oceanos e atmosfera). A área fornece informações, dentre outras, sobre convecção do manto, formação de planetas, origem de granitos e basaltos, sedimentação, mudanças no clima e nos oceanos, origem de depósitos minerais (Albarède, 2011).
Na Geoquímica clássica, o meio ambiente é dividido em compartimentos, desde o universo (macrocosmo), passando pelas rochas, até o solo (microcosmo). Nessa abordagem, os compartimentos são reunidos de forma a compor o conhecido ciclo geoquímico. No entanto, as relações do ser humano com a natureza foram se modificando de forma complexa ao longo do tempo, trazendo a necessidade da compreensão das interações entre homem e meio ambiente e das alterações ambientais ocasionadas por ele. Com isso, surgia um novo ramo da aplicação da geoquímica - a Geoquímica Ambiental, a qual passou a incluir o estudo das mudanças ambientais realizadas pela intervenção humana, ou seja, a antroposfera, e consequentemente: a observação das alterações nos ciclos biogeoquímicos, a identificação de fontes de 
poluentes, os processos de contaminação ambiental, a discussão sobre alterações do clima, o planejamento e exploração eficiente de recursos naturais. No novo contexto, a Geoquímica Ambiental passa a ter um caráter de interdisciplinaridade com as Ciências Naturais, Sociais e Econômicas (Carvalho et al., 1989, Teixeira et al., 2009, Rohde, 2013).

O Programa de Pós-Graduação em Geociências (Geoquímica) (PPGG/UFF), da Universidade Federal Fluminense, pretende diante deste cenário desenvolver o ensino e a pesquisa de forma integrada, assim como busca agregar conhecimentos de diferentes áreas das Ciências (Geologia, Química e Biologia), promovendo a conscientização do papel dos futuros geocientistas na sociedade moderna. O PPGG/UFF foi criado em 1972 e atualmente possui três linhas de pesquisa: (1) Biogeoquímica Ambiental; (2) Contaminação, Degradação e Recuperação Ambiental; (3) Paleoambiente, Paleoclima e Mudanças Globais (PPGG/UFF, 2020).

Com vistas ao perfil do curso, foi oportunizado pelo PPGG/UFF a criação de uma disciplina por três pós-doutorandas (autoras deste manuscrito), bolsistas do Programa Nacional de Pós Doutorado/ Capes (PNPD/CAPES), sendo duas biólogas e uma química, atuantes nas linhas de pesquisas: Contaminação, Degradação e Recuperação Ambiental e Biogeoquímica Ambiental. Com isso, a disciplina intitulada "Tópicos Especiais em Geoquímica: Dinâmica de nutrientes e poluentes metálicos nos compartimentos ambientais" foi oferecida, como disciplina eletiva no segundo semestre do ano de 2016 sendo supervisionada por um professor pertencente ao corpo docente permanente do PPGG/ UFF. Na disciplina, buscou-se um entendimento interligado dos diversos processos biogeoquímicos, a fim de desenvolver no discente, uma visão integralizada sobre a dinâmica (origens, transporte e transformações) dos diversos elementos (nutrientes, poluentes metálicos e radiotraçadores artificiais) entre os compartimentos ambientais (atmosfera, litosfera, hidrosfera e biosfera) e as influências das atividades humanas nos processos naturais.

$\mathrm{Na}$ proposta da disciplina procurou-se incorporar a perspectiva interdisciplinar para além da comunicação de ideias entre disciplinas e/ou conhecimentos de diferentes áreas, conforme classicamente definida. Enquanto prática docente, nos apropriamos dessa perspectiva como uma "atitude de ousadia e busca frente ao conhecimento", a qual necessita "envolver a cultura do lugar" (Fazenda, 2008, p. 94). Assim, em se tratando de formação profissional:
A interdisciplinaridade na formação profissional requer competências relativas às formas de intervenção solicitadas e às condições que concorrerem ao seu melhor exercício. Neste caso, os desenvolvimentos das competências necessárias requerem a conjugação de diferentes saberes disciplinares. Entenda-se por saberes disciplinares: saberes da experiência, saberes técnicos e saberes teóricos interagindo dinamicamente sem nenhuma linearidade ou hierarquização que subjugue os profissionais participantes. (Barbier, 1996, Tardiff, 1990, Gauthier, 1996, citados por Fazenda, 2008, p. 99).

Esta perspectiva na prática docente, visa sobretudo agregar os saberes dos discentes e favorecer o processo de aprendizagem. Ademais, vale destacar que a interdisciplinaridade vem ganhando visibilidade nos debates acadêmicos nos cursos de graduação e pós-graduação nas universidades brasileiras devido à necessidade da integração do conhecimento para a solução dos problemas atuais da sociedade (Pereira \& Nascimento, 2016; Schenini, 2020). Este trabalho consiste em um relato sobre a experiência em desenvolver e ministrar uma disciplina de Pós-graduação na área da Geoquímica Ambiental, integrando os diversos saberes para proporcionar e ampliar a capacidade crítica dos discentes face aos novos desafios da sociedade contemporânea.

\section{Materiais, Métodos e Técnicas}

\section{Público-alvo}

A disciplina contou com seis discentes oficialmente inscritos na PPGG/UFF, sendo quatro mestrandos e dois doutorandos. A turma era composta por profissionais de diferentes formações: dois Geólogos, um Arqueólogo, um Biólogo, um Engenheiro Florestal e um Engenheiro Agrícola. Além desses, um Geólogo e um discente de graduação do curso de bacharelado em Química, participaram como ouvintes. A presença dos ouvintes foi motivada pelo interesse em adquirir embasamento teórico para o ingresso ao PPGG/UFF, por meio de processo seletivo, no período seguinte.

\section{Desenvolvimento da disciplina}

A disciplina foi iniciada com uma aula inaugural, na qual foi apresentado um cronograma geral do curso contendo informações sobre o conteúdo programático de cada módulo, a proposta de aulas

\begin{tabular}{c|c|c|c|c|c|}
\hline (C) Terrae Didat. & Campinas, SP & v.16 & $1-12$ & $\mathrm{e} 020048$ & 2020 \\
\hline
\end{tabular}


práticas, as formas de avaliação e a bibliografia adotada. A carga horária total foi de $60 \mathrm{~h}$, sendo $45 \mathrm{~h}$ teórica e $15 \mathrm{~h}$ prática. As aulas teóricas foram distribuídas em três módulos de $15 \mathrm{~h}$. O recurso didático utilizado para as aulas teóricas incluiu: computador e datashow. O conteúdo programático da disciplina foi distribuído nos módulos: i) Dinâmica de nutrientes nos ecossistemas florestais; ii) Radiotraçadores Artificiais e iii) Poluentes metálicos e modelos integradores. Uma descrição detalhada do conteúdo e instrumentos de ensino utilizados é encontrada a seguir, na ordem de realização durante o semestre:

- Módulo 1 - Dinâmica de nutrientes nos ecossistemas florestais: ciclo hidrológico e balanço de água nos ecossistemas terrestres; deposições atmosféricas (chuva, partículas atmosféricas e gases); dinâmica, interações e transferências de nutrientes entre a atmosfera e os ecossistemas florestais; fontes naturais e antrópicas; balanço de nutrientes.

- Módulo 2-Radiotraçadores Artificiais: radioatividade natural e artificial nos compartimentos ambientais; metodologia de radiotraçadores artificiais; princípios básicos e normas de radioproteção; aplicação da metodologia dos radiotraçadores artificiais em estudos ambientais.

- Módulo 3 - Metais e modelos integradores: metais: fontes e transporte entre compartimentos ambientais; comportamento de metais em ecossistemas terrestres e aquáticos; modelos integradores: Índices de qualidade ambiental (água, sedimento, atmosfera); modelos integradores: bioindicadores, biomarcadores e testes de toxicidade.

As aulas práticas compreenderam as atividades de trabalho de campo (coleta de amostra ambiental) e laboratoriais (tratamento da amostra e análises químicas) que foram realizadas de forma conjunta entre os docentes e discentes. No trabalho de campo foram coletadas seis amostras de água de chuva de um único evento de precipitação, que ocorreu no dia 15 de outubro. Os coletores de água de chuva consistiam em um frasco de plástico de polipropileno, acoplado a um funil de plástico de polietileno de alta densidade (PEAD) de $11,3 \mathrm{~cm}$ de diâmetro, que foi fixado diretamente a um tubo de PVC à 1,5 m de altura do solo (Costa \& de Mello, 1997). Os discentes participaram efetivamente no preparo, descontaminação e instalação dos coletores de água de chuva antes da precipitação e, na coleta das amostras e após seu término. Ainda em campo, os volumes de chuva foram medidos individualmente e anotados (para posterior cálculo da precipitação em milímetros de chuva) e as amostras encaminhadas para o laboratório de Geoquímica da UFF.

No laboratório, os volumes totais das amostras de água de chuva de um único evento de precipitação coletadas em 6 coletores de deposição total foram reunidos e misturados juntos em um frasco de 10L para a obtenção de uma amostra composta. Aproximadamente $500 \mathrm{~mL}$ da amostra composta foram filtrados em filtro de acetato de celulose de $0,22 \mu \mathrm{m}$ de porosidade. Em alíquota não filtrada foram medidos $\mathrm{pH}$ e condutividade elétrica. Alíquotas filtrada e não filtrada da amostra composta foram reservadas para o estudo do comportamento de adsorção dos metais (zinco, cobalto e manganês), utilizando radiotraçadores artificiais ${ }^{65} \mathrm{Zn}$; ${ }^{57} \mathrm{Co} \mathrm{e}{ }^{54} \mathrm{Mn}$ ) no material particulado presente na amostra de água da chuva. A técnica empregada foi uma adaptação da metodologia de fracionamento para a separação do material particulado (Duursma \& Bosch, 1970, Templeton et al., 2000, Souza et al., 2017).

Como parte do planejamento da aula prática, esperava-se que além do estudo dos radiotraçadores artificiais supracitados, fossem também determinadas as concentrações dos metais correspondentes a esses radioisótopos: zinco, cobalto e manganês, em alíquotas filtrada e não filtrada da amostra de água da chuva para alimentar os modelos (índices) ambientais. Com isso, a ideia de integração de saberes já seria iniciada a partir da articulação dos três módulos pela utilização da técnica metodológica de radiotraçador, aprendida no módulo 2 , e da quantificação dos metais correspondentes, abordados no módulo 3, em uma amostra de chuva (precipitação), matriz ambiental estudada no módulo 1, para então, utilizar a concentração desses metais nos modelos (índices) ambientais, além de, discutir o comportamento deles nos compartimentos ambientais e como a contaminação ambiental pode alterar a sua toxicidade nos organismos vivos. Entretanto, por conta de problemas técnicos com o equipamento de absorção atômica, não foi possível determinar as concentrações dos metais supracitados nas alíquotas de água da chuva, sendo utilizados dados de outras fontes para a aplicação nos modelos ambientais do módulo 3, sem, contudo, comprometer a proposta da atividade e a visão integradora da disciplina.

\begin{tabular}{c|c|c|c|c|c}
\hline (C) Terrae Didat. & Campinas, SP & v.16 & $1-12$ & $\mathrm{e} 020048$ & 2020 \\
\hline
\end{tabular}




\section{Metodologia para a avaliação e análise do desempenho dos discentes}

No Módulo 1 foram realizadas duas avaliações. A primeira $\left(A v_{1} 1\right)$, foi composta por uma lista de exercícios contendo dez questões, sendo nove dissertativas e uma de múltipla escolha. As questões dissertativas compreenderam os seguintes temas: ciclo hidrológico, deposições atmosféricas, material particulado atmosférico, atividades antrópicas relacionadas com as emissões dos gases do efeito estufa e dinâmicas do nitrogênio, fósforo, enxofre e do potássio. A questão de múltipla-escolha buscou correlacionar as diversas reações biológicas e químicas que caracterizam os principais processos biogeoquímicos dos elementos supracitados. Cada questão teve como valor 1 ponto. $\mathrm{Na}$ segunda avaliação $\left(A v_{2} 1\right)$, foi proposto que os discentes realizassem uma resenha a partir da leitura de um artigo escolhido por eles, que ao mesmo tempo abrangesse um dos temas abordados e que apresentassem correlação com seu projeto de pesquisa. A resenha deveria incluir a opinião deles sobre a discussão apresentada pelos autores, bem como, a relevância do conteúdo para o seu projeto de pesquisa. Ambas as avaliações totalizaram 10 pontos e tiveram como prazo de entrega final o último dia de aula desse módulo.

O Módulo 2 foi composto por duas avaliações. Na primeira $\left(A v_{1} 2\right)$, foi aplicado um estudo dirigido individual, com o objetivo de relacionar os conteúdos adquiridos nas aulas teóricas com pesquisas que abordassem publicações recentes envolvendo aspectos aplicados à área de radiotraçadores artificiais. Este estudo foi dividido em quatro questões, nas quais foi requisitada a elaboração de um resumo, sendo três questões baseadas na leitura de três artigos escolhidos pela docente (tecnologia de irradiação por elétrons ou fonte de ${ }^{60} \mathrm{Co}$; tardígrado e mesocosmo) e uma questão de escolha livre (referência nacional publicada no mesmo ano da realização da disciplina). Cada questão teve valor de 2,5 totalizando dez pontos. Foi colocada também uma questão extra (sem pontuação) pedindo a opinião do discente em relação ao Módulo 2. A segunda avaliação $\left(A v_{2} 2\right)$ foi a confecção do relatório da aula prática em dupla, composto por introdução, objetivo, material e métodos, resultados, discussão, conclusão e referências bibliográficas. O relatório valia dez pontos.

No módulo 3 , a avaliação proposta $(A v, 3)$ consistiu na aplicação de modelos integradores de parâmetros ambientais usando dados secundários, para discussão integrada dos conteúdos discutidos nos três módulos. Os discentes escolheram tanto os modelos quanto os dados secundários com os quais queriam trabalhar. A escolha foi do discente, justamente, para que o mesmo, pudesse trabalhar seus dados da dissertação ou tese com outros olhos, usando outro viés de investigação, com uma nova interpretação para seus dados. Alguns escolheram, por exemplo, calcular índices de contaminação de sedimentos por metais como o $\mathrm{Zn}$ e o $\mathrm{Mn}$, enquanto outros, calcularam índices de qualidade de água, utilizando-se de dados físico-químicos e concentração de nutrientes adquiridos na literatura (dados secundários). O prazo de entrega foi de 15 dias, e durante este tempo, dúvidas nos cálculos e no tratamento de dados foram sanadas fora de sala de aula. Os trabalhos constituíam de quatro partes: (1) uma introdução sobre o problema ambiental estudado, demonstrando o grupo de dados e o modelo utilizados; (2) demonstração dos cálculos; (3) resultados e críticas ao modelo; e, (4) referências. A avaliação totalizava 10 pontos.

O cálculo da nota final da disciplina foi obtido pela média aritmética das notas das avaliações de cada módulo (Módulo 1, Módulo 2 e Módulo 3). Todas as avaliações tiveram mesmo peso. Para o cálculo da nota final, as avaliações foram ordenadas de acordo com os módulos propostos, conforme a seguir:

\section{Nota Final $=$}

$\underline{(\text { Nota Av Módulo 1) + (Nota Av Módulo 2) + (Nota Av Módulo 3) }}$

\footnotetext{
Onde: $\bar{x}_{\text {nota } A v}$ Módulo 1 = média entre $A v_{1} 1$ e $A v_{2} 1$

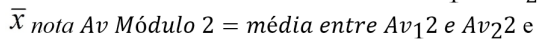
nota Av Módulo $3=A v_{1} 3$.
}

\section{Metodologia de avaliação da disciplina e dos docentes pelos discentes}

Para a avaliação da disciplina e dos docentes, optou-se por uma análise investigativo-exploratória segundo Lüdke \& Andre (1986). Nessa abordagem foram analisados dados de dois questionários elaborados pelas docentes, um para a avaliação da disciplina (Tab. 1) e o outro, para a avaliação das docentes (Tab. 2), aplicados aos discentes no último dia de aula. O primeiro questionário apresenta quatorze perguntas/afirmativas fechadas contendo respostas ordenadas em escala Likert, com cinco 
alternativas de respostas. O segundo é formado por onze perguntas/afirmativas, nove fechadas e duas abertas. As questões/afirmativas fechadas apresentaram respostas ordenadas em escala Likert, sendo quatro delas com três alternativas e as demais com cinco alternativas de respostas. Todos os discentes responderam os questionários e as respostas obtidas foram compiladas e analisadas utilizando-se o programa Microsoft Excel 2010. É importante mencionar que a identidade dos discentes se manteve preservada ao longo da apresentação e discussão dos resultados no presente artigo.

Tabela 1. Questionário aplicado aos discentes para avaliação da atuação docente

\begin{tabular}{|c|c|}
\hline Questões & Respostas \\
\hline $\begin{array}{l}\text { 1) Estimula } \\
\text { interesse pela } \\
\text { matéria? }\end{array}$ & $\begin{array}{l}\text { 4-estimula muito } \\
\text { 3-geralmente estimula } \\
\text { 2-ocasionalmente estimula } \\
\text { 1-não estimula } \\
0 \text {-diminui o interesse do aluno }\end{array}$ \\
\hline $\begin{array}{l}\text { 2) Domina } \\
\text { conteúdo que } \\
\text { está ensinando? }\end{array}$ & $\begin{array}{l}\text { 4-parece dominar muito bem } \\
\text { 3-parece dominar bem } \\
\text { 2-parece ter domínio adequado } \\
\text { 1-parece ter algumas deficiências } \\
\text { 0-parece não ter domínio }\end{array}$ \\
\hline $\begin{array}{l}\text { 3) Explica } \\
\text { princípios e } \\
\text { conceitos do } \\
\text { conteúdo? }\end{array}$ & $\begin{array}{l}\text { 4-muito claro e elucidativo } \\
\text { 3-bastante elucidativo } \\
\text { 2-geralmente elucidativo } \\
\text { 1-dificilmente vai além do livro } \\
\text { 0-deixa muitas dúvidas }\end{array}$ \\
\hline $\begin{array}{l}\text { 4) Usa } \\
\text { exemplos e } \\
\text { ilustrações ao } \\
\text { expor a matéria? }\end{array}$ & $\begin{array}{l}\text { 4-usa sempre e bem } \\
\text { 3-geralmente usa bem } \\
\text { 2-usa adequadamente } \\
\text { 1-raramente usa } \\
0 \text {-nunca usa ou usa mal } \\
\end{array}$ \\
\hline $\begin{array}{l}\text { 5) Considera a } \\
\text { experiência do } \\
\text { aluno? }\end{array}$ & $\begin{array}{l}\text { 4-sempre considera } \\
\text { 3-geralmente leva isso em conta } \\
\text { 2-ocasionalmente considera } \\
\text { 1-parece supor irrelevante considerar } \\
0 \text {-nunca considera }\end{array}$ \\
\hline $\begin{array}{l}\text { 6) Demonstra } \\
\text { preocupação } \\
\text { com o } \\
\text { aprendizado do } \\
\text { aluno? }\end{array}$ & $\begin{array}{l}\text { 4-sempre demonstra } \\
\text { 3-quase sempre demonstra } \\
\text { 2-ocasionalmente demonstra } \\
\text { 1-raramente se preocupa } \\
\text { 0-parece não ser problema dele }\end{array}$ \\
\hline $\begin{array}{l}\text { 7) Demonstra } \\
\text { planejar as } \\
\text { aulas? }\end{array}$ & $\begin{array}{l}\text { 4-parece sempre planejar } \\
\text { 3-geralmente planeja } \\
\text { 2-ocasionalmente planeja } \\
\text { 1-raramente planeja } \\
\text { 0-nunca parece planejar }\end{array}$ \\
\hline $\begin{array}{l}\text { 8) Exige } \\
\text { raciocínio do } \\
\text { aluno? }\end{array}$ & $\begin{array}{l}\text { 4-sempre exige } \\
\text { 3-geralmente exige } \\
\text { 2-ocasionalmente exige } \\
\text { 1-raramente exige } \\
0 \text {-nunca exige }\end{array}$ \\
\hline
\end{tabular}

\begin{tabular}{|c|c|}
\hline $\begin{array}{l}\text { 9) Estimula o } \\
\text { senso crítico do } \\
\text { aluno? }\end{array}$ & $\begin{array}{l}\text { 4-estimula muito } \\
\text { 3-geralmente estimula } \\
\text { 2-ocasionalmente estimula } \\
\text { 1-não estimula } \\
\text { 0-desestimula }\end{array}$ \\
\hline $\begin{array}{l}\text { 10) Estabelece } \\
\text { relações entre } \\
\text { teoria e prática? }\end{array}$ & $\begin{array}{l}\text { 4-sempre estabelece } \\
\text { 3-geralmente estabelece } \\
\text { 2-ocasionalmente estabelece } \\
\text { 1-raramente estabelece } \\
\text { 0-nunca estabelece }\end{array}$ \\
\hline $\begin{array}{l}\text { 11) É acessível } \\
\text { aos alunos em } \\
\text { classe? }\end{array}$ & $\begin{array}{l}\text { 4-é muito acessível } \\
\text { 3-geralmente é acessível } \\
\text { 2-ocasionalmente é acessível } \\
\text { 1-cria barreiras com os alunos } \\
\text { 0-é totalmente inacessível } \\
\end{array}$ \\
\hline $\begin{array}{l}\text { 12) É acessível } \\
\text { aos alunos fora } \\
\text { de classe? }\end{array}$ & $\begin{array}{l}\text { 4-é muito acessível } \\
\text { 3-geralmente é acessível } \\
\text { 2-ocasionalmente é acessível } \\
\text { 1-procura manter distância dos alu- } \\
\text { nos } \\
\text { 0-é totalmente inacessível }\end{array}$ \\
\hline $\begin{array}{l}\text { 13) É assíduo e } \\
\text { pontual? }\end{array}$ & $\begin{array}{l}\text { 4-sempre é assíduo e pontual } \\
\text { 3-é muito assíduo e pontual } \\
\text { 2-às vezes falta ou se atrasa } \\
\text { 1-falta e/ou se atrasa frequentemente } \\
\text { 0-falta e/ou se atrasa muito }\end{array}$ \\
\hline $\begin{array}{l}\text { 14) } \\
\text { Recomendaria } \\
\text { aulas destas } \\
\text { professoras aos } \\
\text { seus colegas? }\end{array}$ & $\begin{array}{l}\text { 4-recomendaria fortemente } \\
\text { 3-recomendaria } \\
\text { 2-recomendaria com reservas } \\
\text { 1-desaconselharia } \\
\text { 0-desaconselharia fortemente }\end{array}$ \\
\hline
\end{tabular}

Tabela 2. Questionário aplicado aos discentes para avaliação da disciplina Tópicos Especiais em Geoquímica

\begin{tabular}{|c|c|}
\hline Questões & Respostas \\
\hline $\begin{array}{l}\text { 1) O conteúdo } \\
\text { proposto se } \\
\text { adequa ao título } \\
\text { da disciplina? }\end{array}$ & $\begin{array}{l}\text { 4-sim, completamente } \\
\text { 2-sim, parcialmente } \\
\text { 0-não }\end{array}$ \\
\hline $\begin{array}{l}\text { 2) Na sua } \\
\text { opinião, houve } \\
\text { uma integração } \\
\text { de conteúdos? }\end{array}$ & $\begin{array}{l}\text { 4-sim, completamente } \\
\text { 2-sim, parcialmente } \\
\text { 0-não }\end{array}$ \\
\hline $\begin{array}{l}\text { 3) Como } \\
\text { você avaliaria } \\
\text { a divisão em } \\
\text { módulos? }\end{array}$ & $\begin{array}{l}\text { 4- facilitou o entendimento do con- } \\
\text { teúdo } \\
\text { 3- facilitou, mas não deixou clara a } \\
\text { integração entre módulos } \\
\text { 2- indiferente } \\
\text { 1- não facilitou no entendimento } \\
\text { 0- foi mais difícil a compreensão dos } \\
\text { conteúdos }\end{array}$ \\
\hline $\begin{array}{l}\text { 4) Como você } \\
\text { avaliaria as aulas } \\
\text { teóricas? }\end{array}$ & $\begin{array}{l}\text { 4- boa definição de carga horária } \\
\text { 3- poderiam durar mais } \\
\text { 2- poderia ser menor a carga horária } \\
\text { de aula teórica } \\
\text { 1- indiferente }\end{array}$ \\
\hline \multicolumn{2}{|c|}{ * Continua na próxima página } \\
\hline v.16 & \begin{tabular}{l|l}
$1-12$ & $\mathrm{e} 020048$ \\
\end{tabular} \\
\hline
\end{tabular}


* Continuação da Tabela 2

4- boa definição de carga horária

3- poderiam durar mais

5) E as aulas 2- poderia ser menor a carga horária

práticas?

de aula teórica

1- indiferente

6) Os exercícios

propostos $\quad 4$-sim, completamente

auxiliaram no 2-sim, parcialmente

entendimento 0 -não

de conteúdos?

\begin{tabular}{|c|c|}
\hline $\begin{array}{l}\text { 7) As avaliações } \\
\text { foram } \\
\text { adequadas? }\end{array}$ & $\begin{array}{l}\text { 4-sim, completamente } \\
\text { 2-sim, parcialmente } \\
\text { 0-não }\end{array}$ \\
\hline $\begin{array}{l}\text { 8) Importância } \\
\text { desta disciplina }\end{array}$ & $\begin{array}{l}\text { 4-é muito importante } \\
\text { 3-é importante } \\
\text { 2-talvez seja importante } \\
\text { 1-é pouco importante } \\
\text { 0-não é importante } \\
\end{array}$ \\
\hline $\begin{array}{l}\text { 9) Importância } \\
\text { do que aprendi } \\
\text { nesta disciplina }\end{array}$ & $\begin{array}{l}\text { 4-foi muito importante } \\
\text { 3-foi importante } \\
\text { 2-foi razoavelmente importante } \\
\text { 1-foi pouco importante } \\
\text { 0-não foi importante }\end{array}$ \\
\hline $\begin{array}{l}\text { 10) Cite pontos } \\
\text { positivos da } \\
\text { disciplina }\end{array}$ & Pergunta aberta \\
\hline $\begin{array}{l}\text { 11) Cite pontos } \\
\text { negativos da } \\
\text { disciplina }\end{array}$ & Pergunta aberta \\
\hline
\end{tabular}

\section{Análise da disciplina pelas docentes}

$\mathrm{Na}$ análise da disciplina discutiram-se os objetivos da disciplina a partir de uma avaliação crítica realizada pelas docentes, apontando os pontos positivos e negativos, focalizando: (1) motivação dos discentes; (2) integração de conteúdos; (3) aula prática integrada; (4) avaliações; (5) problemas encontrados.

\section{Resultados e Discussão}

\section{Análise e avaliação do desempenho dos discentes pelas docentes}

Neste tópico são discutidas as percepções das docentes quanto a avaliação quantitativa e o desempenho dos discentes, com vistas às estratégias pedagógicas adotadas na disciplina.

A Tabela 3 apresenta as notas das avaliações por módulos dos discentes. As avaliações incluíram as atividades teóricas e práticas. As notas médias dos discentes por módulos foram superiores a 7,0, exceto para dois discentes que tiveram nota 6,5 no módulo 3. O relatório da prática do módulo 2 foram elaborados e entregues pelos discentes em tempo estabelecido, as notas foram boas (média $=7,8)$ e o interesse e a participação dos discentes na aula prática foram excelentes (presença $=$ 100\%). Apesar de um dos discentes, ouvinte, não ter entregado a lista de exercícios do módulo 2 (por problemas pessoais), todos os discentes foram aprovados. A média geral da turma, considerando os três módulos foi 8,1, variando entre 7,1-9,1.

Com relação ao módulo 1 , foi observado que a utilização de vídeos didáticos de curta duração (de até 15 minutos) como recurso pedagógico, mostrou-se uma ferramenta chave para a motivação do debate entre os discentes e a docente, já que os discentes possuíam diferentes formações acadêmicas, podendo contribuir com diferentes olhares sobre o mesmo assunto. Os vídeos foram apresentados ao final de aula, sendo classificados como informativos ou documentários, tendo sido selecionados de sites de instituições de pesquisa nacionais ou internacionais para contextualizar o assunto abordado. Este

Tabela 3. Avaliação quantitativa dos discentes da disciplina Tópicos Especiais em Geoquímica

\begin{tabular}{|c|c|c|c|c|c|c|c|c|}
\hline \multirow[b]{2}{*}{ Notas } & \multicolumn{3}{|c|}{ Módulo 1} & \multicolumn{3}{|c|}{ Módulo 2} & \multirow{2}{*}{$\begin{array}{c}\text { Módulo } 3 \\
\text { Trabalho } \\
\text { (M3) }\end{array}$} & \multirow{2}{*}{$\begin{array}{l}\text { Média } \\
\text { Final }\end{array}$} \\
\hline & Exerc. & Resumo & $\begin{array}{c}\text { Média } \\
\text { (M1) }\end{array}$ & Exerc. & Relat. & $\begin{array}{c}\text { Média } \\
\text { (M2) }\end{array}$ & & \\
\hline Estudante 1 & 7,8 & 7,5 & 7,7 & 7,0 & 7,5 & 7,3 & 6,5 & 7,1 \\
\hline Estudante 2 & 8,6 & 8,0 & 8,3 & 7,0 & 8,5 & 7,8 & 6,5 & 7,5 \\
\hline Estudante 3 & 9,0 & 9,0 & 9,0 & 9,5 & 8,0 & 8,8 & 9,5 & 9,1 \\
\hline Estudante 4 & 7,6 & 8,0 & 7,8 & 9,5 & 8,0 & 8,8 & 8,0 & 8,2 \\
\hline Estudante 5 & 8,6 & 9,3 & 9,0 & 9,0 & 8,5 & 8,8 & 8,5 & 8,7 \\
\hline Estudante 6 & 8,1 & 9,3 & 8,7 & 7,5 & 7,5 & 7,5 & 8,5 & 8,2 \\
\hline Ouvinte 1 & 8,4 & 8,5 & 8,5 & $\star$ & 8,5 & 4,3 & 9,0 & 7,2 \\
\hline Ouvinte 2 & 8,2 & 8,8 & 8,5 & 10,0 & 7,5 & 8,8 & 8,5 & 8,6 \\
\hline
\end{tabular}

Exerc. $=$ Exercício; Relat. $=$ Relatório; ${ }^{*}$ Trabalho não entregue. 
recurso promoveu uma maior dinâmica e interação na turma, e vem sendo apontado como importante ferramenta de apoio ao processo de aprendizagem (Pazzini \& Araujo, 2015; Borba \& Oechsler, 2018). Outros aspectos relevantes foram o desenvolvimento de exercícios em sala de aula e a aplicação de listas de exercícios de fixação, contendo exemplos baseados em estudos publicados em artigos científicos, que envolviam cálculos matemáticos e conversão de unidades. Entretanto, o fator prazo de entrega da resolução das listas de exercícios foi insatisfatório. Uma dificuldade encontrada foi o fato de que as listas eram complexas, com exercícios longos e trabalhosos, o que exigiu grande esforço e tempo de execução acima do previsto. Nas aulas do módulo 1 foram projetadas atividades laboratoriais, tais como demonstrações das principais metodologias para a determinação química de compostos de nitrogênio e fósforo em matrizes ambientais, porém, devido ao limitado de tempo de aula destinado para cada módulo e o conteúdo extenso das aulas teóricas, optou-se por excluir as aulas práticas individuais deste módulo da disciplina e manter a prática de campo (coleta de amostra de água de chuva) e laboratório (caracterização físico-química e determinação de nutrientes - nitrogênio e fósforo dos radiotraçadores) programada para ser realizada como avaliação conjunta (entre os três módulos) no final da disciplina. A turma apresentou rendimento satisfatório nas aulas. As notas foram consideradas boas e/ou muito boas e os discentes mostraram-se interessados e participativos na aula. Além disso, os discentes foram assíduos e pontuais.

No módulo 2, durante os tempos de aula teórica apesar dos discentes apresentarem grande interesse pelo tema, a participação foi satisfatória. Como o assunto deste módulo possuía conceitos teóricos que não são muitas vezes abordados anteriormente na graduação, foi gasto pela docente, um tempo maior no desenvolvimento do conteúdo, comprometendo a compreensão e o avanço de tópicos aplicados. Isso fica evidente, quando foi perguntado aos discentes qual o tópico sobre metodologia de radiotraçadores eles mais gostaram e qual o assunto que eles gostariam que fosse incluído e/ ou aprofundado. Um dos discentes relatou a dificuldade no entendimento da aplicação da técnica de radiotraçadores no meio ambiente:

"A aula de Metodologia de Radiotraçadores em estudos ambientais foi novidade para mim, pois nunca trabalhei com nada a respeito. Ao procurar os artigos para responder a presente lista, pude ver como é amplo o uso/finalidade dos radiotraçadores. Achei muito interessante o fato de como sua aplicação pode ser útil no tratamento de muitas doenças. Seria interessante relatar em aula, a aplicação dos radiotraçadores no meio ambiente, como eles podem ser aplicados e para que finalidade".

Isso provavelmente pode ser justificado pelo fato de ter sido o primeiro contato do discente com o assunto. Apesar disto, quando questionados sobre sugestões de assuntos que poderiam ser incluídos ou aprofundados em aulas futuras, a maioria expressou de forma positiva suas opiniões quanto à ampliação do conhecimento de outras técnicas nucleares; destaca-se a resposta de um deles:

"Com a participação nesta disciplina, consegui
compreender melhor o conceito, função e apli-
cação dos radiotraçadores, como os isótopos e
através desse conhecimento é possível compre-
ender melhor a utilização nas nossas pesquisas
presentes ou futuras. Gostaria que fosse abor-
dado mais sobre o uso dos radiotraçadores na
agricultura, principalmente a respeito do P32 e
entender quando ele fica retido no solo, na planta
ou atmosfera."

A despeito das dificuldades enfrentadas, a maioria dos discentes foi aprovada no Módulo 2 (Tab. 3) com variação das médias de 7,3 a 8,8 com a exceção do ouvinte 1 (média 4,3) por não ter entregado a lista de exercícios. Para um melhor desempenho por parte do docente, a adoção de lista de exercícios a serem entregues no final de cada aula teórica, e não somente no final do Módulo 2, seria uma forma de avaliação prévia e específica do grau de dificuldade dos discentes para serem abordados e discutidos no decorrer das aulas como forma de otimização dos conteúdos e melhoria da eficiência temporal das aulas.

No módulo 3, o conteúdo em si já é integrador, incluindo conceitos e conhecimentos abordados previamente nos módulos 1 e 2 e na parte introdutória do 3. A motivação dos discentes foi maior após a aula introdutória, quando as propostas de índices integradores de informações ambientais foram apresentadas, provavelmente pela visualização da integração de conteúdo. A complexidade dos questionamentos foi mediana, em consequência até mesmo pelo caráter de novidade em termos de conteúdo. Nenhuma das propostas de índices apresentada em sala de aula 
era previamente conhecida. Então a maior parte dos questionamentos foi básica, com o objetivo de elucidar melhor as bases necessárias para os cálculos e aplicações dos índices. Este foi o único módulo que propôs uma única avaliação, entretanto era uma avaliação com proposta integradora de conhecimentos. Cada discente escolheu um conjunto de dados primários, proveniente de seu projeto de pesquisa ou secundários, obtidos da literatura, para a aplicação de um índice integrador de diferentes variáveis ambientais, conforme foi relatado anteriormente. Todavia, observou-se que dos oito discentes, cinco optaram pelo cálculo do mesmo índice (índice do grau de contaminação de sedimentos). Esta opção pode ter sido relacionada à praticidade do cálculo e não necessariamente relacionada à aderência à dissertação ou tese do discente (proposta original).

Desta forma, a avaliação foi capaz de estabelecer a integração de dados, porém por ter deixado a escolha do índice livre, os discentes podem não ter se aprofundado em integrações mais úteis e aplicáveis às suas próprias teses e dissertações. Ou até mesmo, seguido a ideia inicial, trabalhando as concentrações de metais em material particulado atmosférico ou na forma dissolvida em água de chuva, usando entretanto, dados secundários, já que as determinações de metais nas amostras coletadas não puderam ser realizadas por problemas técnicos no equipamento. Outro ponto forte desse tipo de avaliação foi a procura por auxílio fora da sala de aula, tanto para questionamentos sobre os cálculos em si, como para direcionamentos quanto a escolha do índice ou busca de dados secundários. Somente um dos discentes não respeitou o prazo de entrega do trabalho.

\section{Análise e avaliação da disciplina e do desempenho das docentes pelos discentes}

Com base nas respostas dos discentes, tanto a atuação dos docentes (Fig. 1a-h) quanto a abordagem da disciplina (Fig. 2 e Tab. 4) foi muito positiva.

No tocante à atuação das docentes, a maioria dos discentes alegaram que estas revelaram preocupação com o aprendizado, com o planejamento das aulas, com a acessibilidade ao atendimento ao discente e fora da sala de aula e com a assiduidade. Eles relataram que de maneira geral, a atuação das docentes promoveu grande motivação pela disciplina (Fig. $1 \mathrm{a}-\mathrm{h}$ ). Na opinião deles, os conceitos foram explicados de forma muito clara e elucidativa, com exemplos e ilustrações que exigiam raciocínio, contribuindo para o senso crítico e
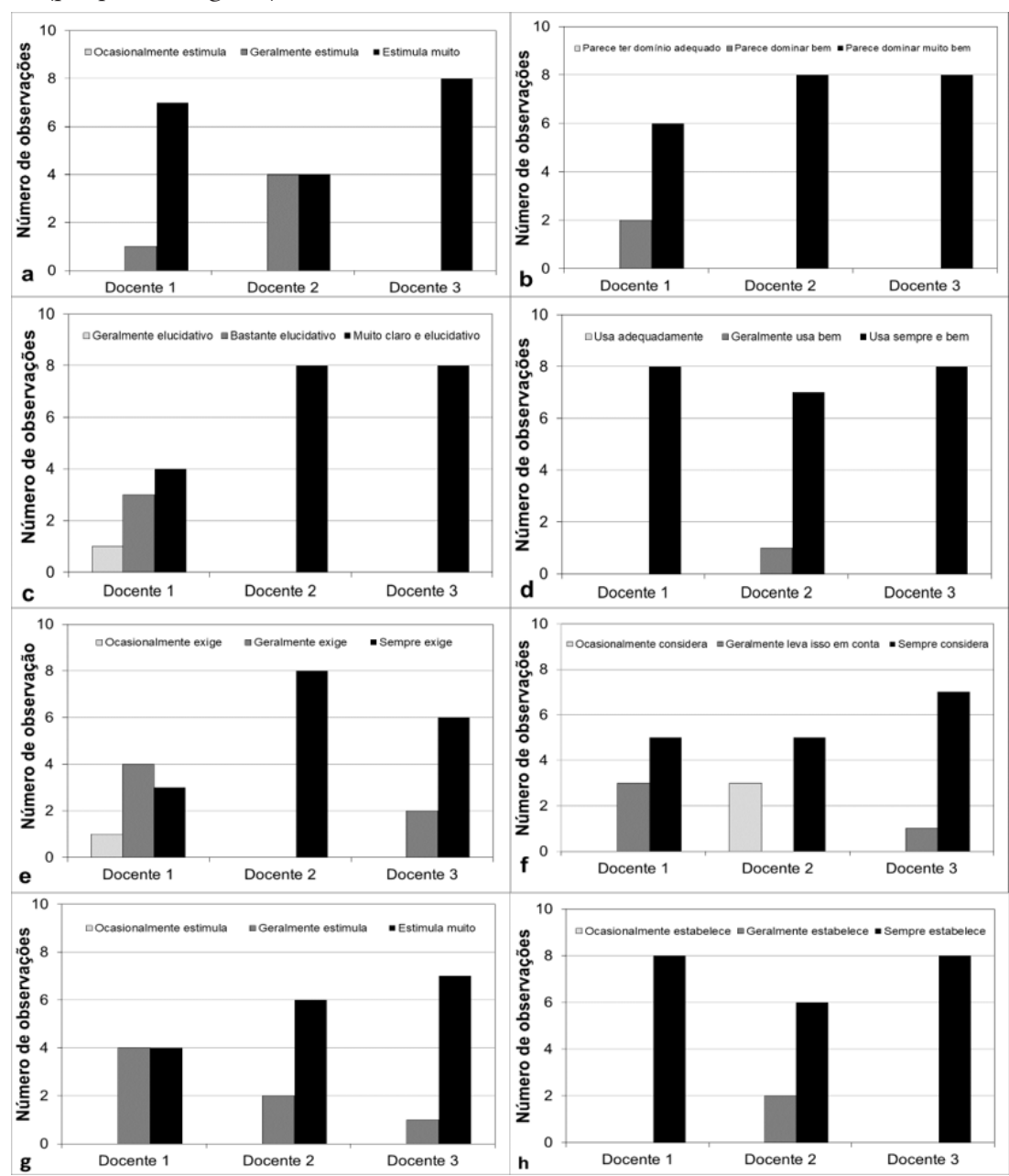

Figura 1. Opinião dos estudantes sobre a atuação docente na disciplina Tópicos Especiais em Geoquímica (Turma 2016-1). a) Estimula interesse pela matéria?; b) Domina conteúdo que está ensinando?; c) Explica princípios e conceitos do conteúdo?; d) Usa exemplos e ilustrações ao expor a matéria?; e) Exige raciocínio do aluno?; f) Considera a experiência do aluno?; g) Estimula o senso crítico do aluno?; h) Estabelece relações entre teoria e prática?

\begin{tabular}{c|c|c|c|c|c}
\hline (C) Terrae Didat. & Campinas, SP & v.16 & $1-12$ & $\mathrm{e} 020048$ & 2020 \\
\hline
\end{tabular}


estabelecimento das relações entre teoria e prática. Eles indicaram também, que as docentes consideraram suas experiências. Além disso, responderam que eles recomendariam essa disciplina aos demais colegas da pós-graduação.

Em relação à disciplina própriamente dita (Fig. 2), a maioria dos discentes considerou os conteúdos da disciplina como muito importantes e completamente adequados ao seu título. Os discentes também concordaram que a forma na qual a disciplina foi conduzida, permitiu integração completa dos conteúdos apresentados. Eles destacaram ainda que os exercícios propostos, bem como, as avaliações como um todo, auxiliaram na compreensão dos temas estudados. A divisão por módulos foi vista por eles como facilitadora do entendimento dos conteúdos ministrados.

Segundo a opinião dos discentes, o principal aspecto positivo proposto foi a inclusão de atividades de campo e laboratório (Tab.4). Eles concordam que tais atividades despertam maior interesse pela disciplina, contribuindo para o conhecimento de novas técnicas de amostragem e métodos analíticos, tratamento, interpretação e discussão dos dados obtidos. Esse fato é verificado na resposta de um dos discentes, “... muito proveitosa a aula prática, foi muito boa a aproximação com os equipamentos, de como se faz a coleta e o tratamento das amostras, são cuidados que só se aprende com a prática."

Nesse sentido, os trabalhos de campo e as aulas práticas vêm sendo reportados na literatura como relevantes para diferentes níveis escolares, desde o ensino fundamental até a pós-graduação (Paschoale, 1984, Morcillo et al., 1998, Santos, 2004, Silva et al., 2010, Justen-Zancanaro \& Carneiro, 2012, Pataca, 2014). Garcia De La Torre (1991) ressalta a importância das saídas de campo no ensino de Ciências, pois uma vez em contato com a realidade, a busca pela compreensão dos fenômenos naturais torna-se mais motivadora, sendo cenários de geração, problematização e crítica do conhecimento, nos quais o conflito entre o real e as ideias ocorre com toda a intensidade.

Dentre os aspectos negativos (Tab. 4), o principal questionamento apontado por eles foi a carga horária total da disciplina. Muitos sugeriram a redução do tempo das aulas teóricas e o aumento do tempo destinado às atividades laboratoriais e

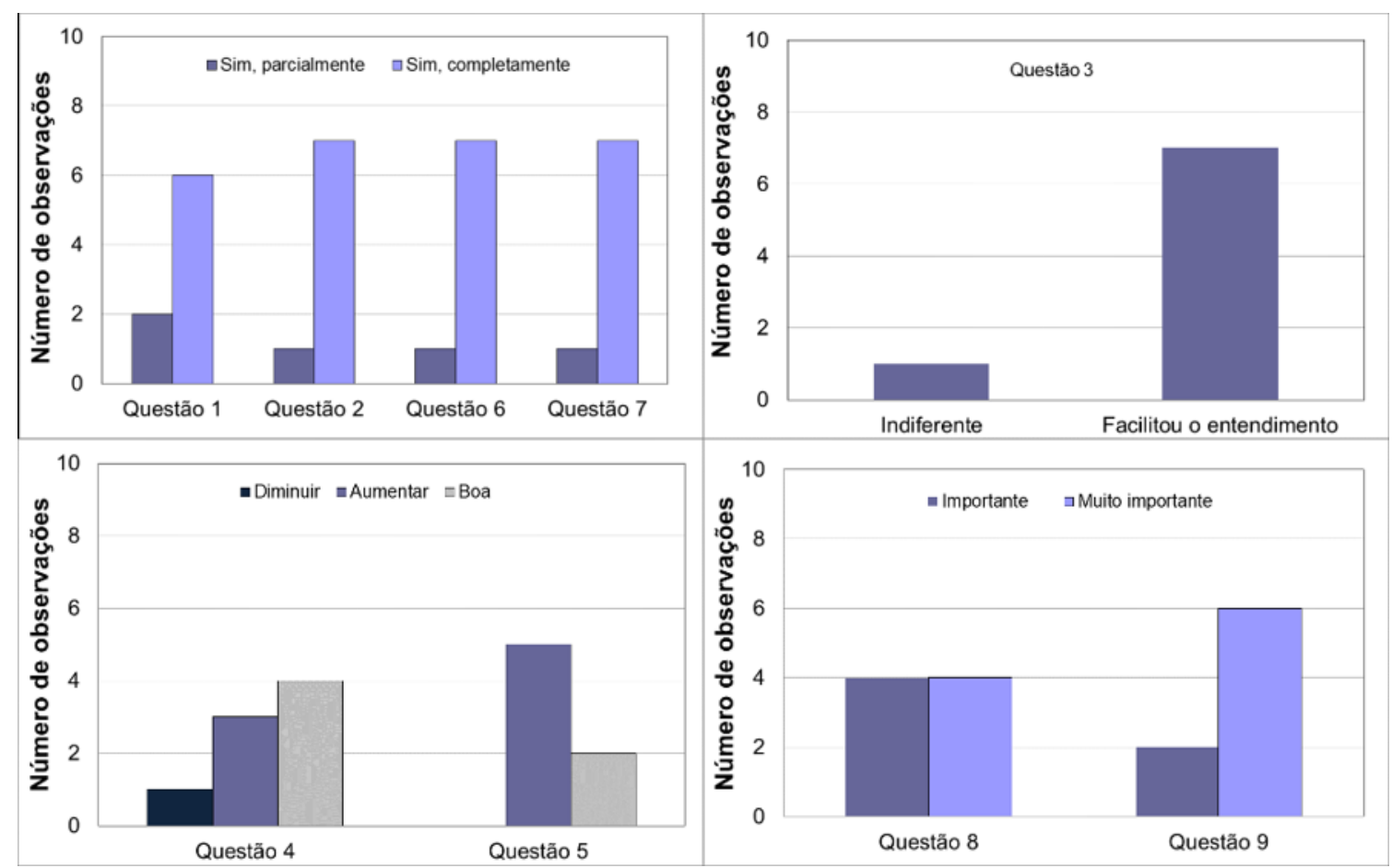

Figura 2. Opinião dos estudantes sobre a disciplina Tópicos Especiais em Geoquímica (Turma 2016-1). Questão 1) O conteúdo proposto se adequa ao título da disciplina?; Questão 2) Na sua opinião, houve uma integração de conteúdos?; Questão 3) Como você avaliaria a divisão em módulos?; Questão 4) Como você avaliaria as aulas teóricas?; Questão 5) E as aulas práticas?; Questão 6) Os exercícios propostos auxiliaram no entendimento de conteúdos?; Questão 7) As avaliações foram adequadas?; Questão 8) Importância desta disciplina; Questão 9) Importância do que aprendi nesta disciplina

\begin{tabular}{c|c|c|c|c|c}
\hline (C) Terrae Didat. & Campinas, SP & v.16 & $1-12$ & $\mathrm{e} 020048$ & 2020 \\
\hline \multicolumn{4}{|c|}{9}
\end{tabular}


Tabela 4. Pontos positivos e negativos da disciplina Tópicos Especiais em Geoquímica, de acordo com os discentes de 2016-1

\begin{tabular}{l|l}
\hline \multicolumn{1}{c|}{ Pontos Positivos } & \multicolumn{1}{c}{ Pontos negativos } \\
\hline $\begin{array}{l}\text { Conteúdo bastante abrangente para o curso de Geoquímica. } \\
\begin{array}{l}\text { Muito bem ministrada. Conteúdo bem completo e coeso, abrangen- } \\
\text { do de tudo um pouco, as profissionais se preocuparam em conhecer } \\
\text { o projeto de estudo dos alunos para tornar as aulas mais proveitosas } \\
\text { possível. Muito proveitosa a aula prática, foi muito boa a aproximação } \\
\text { com os equipamentos, de como de se faz a coleta e o tratamento das } \\
\text { amostras, são cuidados que só se aprende com a prática. }\end{array}\end{array}$ & $\begin{array}{l}\text { Justamente pela grande quantidade de } \\
\text { conteúdo, não é possível aprofundar-se } \\
\text { em alguns temas. Isto não é um aspecto } \\
\text { negativo, mas sim uma observação. Acre- } \\
\text { dito que não poderia ser diferente, dadas } \\
\text { as características da disciplina. }\end{array}$ \\
\hline $\begin{array}{l}\text { Aula prática; Conhecimento de novas técnicas laboratoriais. } \\
\text { A aula prática foi muito interessante, as práticas no laboratório ajudam } \\
\text { a clarear as ideias. }\end{array}$ & Achei a carga prática muito pequena. \\
\hline $\begin{array}{l}\text { Aulas práticas. Em uma única disciplina foi possível ter acesso a assun- } \\
\text { tos diferentes com professoras que atuam em áreas diferentes, integra- } \\
\text { ção de conteúdos distintos. }\end{array}$ & $\begin{array}{l}\text { Certos momentos a teoria fica meio ma- } \\
\text { çante. }\end{array}$ \\
\hline $\begin{array}{l}\text { Assuntos totalmente interessantes. Assuntos que levo para minha } \\
\text { dissertação e assuntos sempre interessantes e muito necessários para } \\
\text { geocientistas como os ciclos dos elementos. Aula prática, apesar de } \\
\text { pequena, se mostrou fundamental à disciplina. }\end{array}$ & $\begin{array}{l}\text { Ponto negativo eu diria que foi a prática } \\
\text { que faltou concluir. } \\
\text { E planejar melhor o tempo, pois em um } \\
\text { dia a aula ultrapassou o horário. }\end{array}$ \\
\hline $\begin{array}{l}\text { Como o conteúdo é bastante amplo e com uma grande quantidade de } \\
\text { conteúdo, a disciplina propicia ao aluno uma visão bastante abrangente } \\
\text { de temas relacionados ao meio ambiente, apresentando aos alunos } \\
\text { conceitos imprescindíveis para a sua formação acadêmica. }\end{array}$ & $\begin{array}{l}\text { A teoria de radionuclídeos é muito ma- } \\
\text { çante. }\end{array}$ \\
\hline
\end{tabular}

de campo, para torná-las menos massivas (Tab. 4). Acredita-se que ao tornar as aulas mais dinâmicas em sala de aula, ressaltando o cotidiano dos discentes e utilizando os diferentes recursos educacionais, o aprendizado se torna melhor e mais efetivo (Jesus, 2010, Silva et al., 2012). A proposta dos discentes vai de encontro ao sugerido por Santos \& Compiani (2009), que indicaram que um trabalho de campo com objetivo investigativo pode assumir papel importante no aprendizado.

Morin (2000) afirmou que a educação do futuro deveria inserir o debate sobre as incertezas, isto é, criar meios por meio dos quais as dúvidas e interrogações do nosso tempo fossem discutidas. Estas seriam algumas das condições necessárias para uma formação cidadã. Interessante citar um estudo realizado com discentes de graduação, que demonstraram o mesmo interesse pelo equilíbrio entre teoria e prática e que acreditam que atividades práticas e trabalhos de campo fazem a diferença na hora da escolha da disciplina (Santos et al., 2013). Adicionalmente, é importante citar estudos que demonstraram que somente aulas expositivas não levam os discentes à perfeita compreensão do conteúdo abordado, tornando-se maçantes e desanimadoras, o que contribui para fácil dispersão e desinteresse (Prigol \& Giannotti, 2008, Paulo et al., 2014).

\section{Considerações Finais}

As respostas dos discentes indicaram que a proposta da disciplina foi, ao menos em parte, alcançada. A maioria dos discentes concordou que os assuntos discutidos nas aulas foram pertinentes e que a execução em módulos ocorreu de forma clara, coesa e motivadora, facilitando a aprendizagem. Eles apontaram que as atividades em campo e as práticas desenvolvidas no laboratório foram essenciais para a visão integradora dos três módulos. Os discentes salientaram a necessidade de aumentar a carga-horária prática e redução das aulas teóricas. Embora parte dos experimentos propostos pelos docentes não pôde ser concluída, o recurso foi apontado como importante ferramenta pedagógica.

Refletir criticamente sobre a proposta de ensino, a partir do olhar das docentes e dos discentes, permitiu identificar questões inerentes ao Ensino de Ciências, acentuando a importância dos trabalhos experimentais e de campo, cuja realização, em qualquer nível de ensino, inclusive na pós-graduação é cercada de desafios. Os módulos serviram de inspiração para proposição de novas disciplinas no programa. Permitiram ainda refletir sobre o conceito de interdisciplinaridade para além da junção de disciplina, mas entendendo-o como práxis docente

\begin{tabular}{c|c|c|c|c|c}
\hline (C) Terrae Didat. & Campinas, SP & v.16 & $1-12$ & $\mathrm{e} 020048$ & 2020 \\
\hline
\end{tabular}


na busca de integração de experiências e de saberes teóricos e técnicos. Uma nova visão do processo de ensino em pós-graduação e estratégias de aprendizagem inovadoras são necessárias para melhor formação profissional, considerando adequação a novas gerações e possibilitando o surgimento de novas tecnologias da educação para auxiliar na superação dos problemas rotineiros.

\section{Agradecimentos}

O presente trabalho foi realizado com o suporte da Coordenação de Aperfeiçoamento de Pessoal de Nível Superior, Brasil (CAPES). As autoras agradecem pelas bolsas PNPD/CAPES e pelo apoio recebido pelos respectivos supervisores, em especial, ao apoio do Prof. Dr. Wilson Thadeu Valle Machado, para a criação e supervisão da disciplina.

\section{Referências}

Albarède, F. (2011). Geoquímica: uma introdução. São Paulo: Oficina de Textos. 202p.

Carvalho, C. N. (1989). Geoquímica Ambiental: Conceitos, Métodos e Aplicações. Geochimica Brasiliensis, 3(1), 17-21, doi: 10.21715/gb.v1i3.21.

Costa, C. M. P., De Mello, W. Z. (1997). Deposições atmosféricas e intercâmbio com a copa da floresta no maciço do Itatiaia, RT, na Estação das Chuvas. Geochimica Brasiliensis, 11(3), 341-354, doi: 10.21715/gb.v11i3.137.

Duursma, E. K., \& Bosch, C. J. (1970). Theoretical, experimental and field studies concerning diffusion of radioisotopes in sediments and suspended particles of the sea. Part b: methods and experiments. The Netherlands Journal of Sea Research, 4(4), 395-469.

Fazenda, I. C. A. (2008). Interdisciplinaridade e transdisciplinaridade na formação de professores. Foz do Iguaçu, Unioeste, Ideação, 10(1), 93-103. URL: http://e-revista.unioeste.br/index.php/ideacao/article/view/4146/3191. Acesso 18.11.2020.

Garcia de La Torre, E. (1991). Recursos en la Enseñanza de la Geología: La Geología de campo. Investigación en la escuela, 13(7), 85-93. doi: 10.12795/IE.1991. i13.07.

Jesus, A. C. A. (2010). Como aplicar jogos e brincadeiras na educação infantil. Rio de Janeiro: Bransport. 100p.

Justen-Zancanaro, R., \& Carneiro, C. D. R. (2012). Trabalhos de campo na disciplina de Geografia: estudo de caso em Ponta Grossa, PR. Terra, 9(1-2), 49-60. URL: http://www.ige.unicamp.br/terrae/ V9/T V9 A5.html. Acesso 13.06.2020.

Lüdke, M., \& Āndré, M. E. D. A. (1986). Pesquisa em Educação: abordagens qualitativas. São Paulo: EPU. 128p.

Morcillo, J. G., Rodrigo, M., Centeno, J. G., \& Compiani, M. (1998). Caracterización de las prácticas de campo: justificación y primeros resultados de una escuesta al professorado. Ensenãnza de las Ciencias de la Tierra, 6(3), 242-248.
Morin, E. (2000). Os Sete Saberes Necessários à Educação do Futuro. São Paulo: Cortez. 104p.

Paschoale, C. (1984). Alice no país da geologia e o que ela encontrou lá. In: Congresso Brasileiro de Geologia. SBG, Rio de Janeiro. URL: http://sbg.sitepessoal.com/anais digitalizados/1984-RIO\%20 DE\%20JANEIRO/CBG.1984.vol.11.pdf. Acesso 25.10.2019.

Pataca, E. M. (2014). História das geociências no estudo do lugar - os trabalhos de campo como agentes articuladores de sequencias didáticas na Região Metropolitana de São Paulo. In: $14^{\circ}$ Seminário Nacional de História da Ciência e da Tecnologia, Universidade Federal de Minas Gerais, Belo Horizonte, 2014. URL: https:// www.14snhct.sbhc.org.br/. Acesso 10.05.2020.

Paulo, A. S. G., Xavier, R. A., \& Dornellas, P. C. (2014). $\mathrm{O}$ ensino de geociências no $1^{\mathrm{O}}$ ano do ensino médio nas escolas de Arapiraca (AL). Geosaberes, 5(10), 04-16. URL:

Pereira, E. Q., \& Nascimento, E. P. (2016). A interdisciplinaridade nas universidades brasileiras: trajetória e desafios, Redes (St. Cruz Sul, Online), 21(1), 209232. doi: 10.17058/redes.v21i1.4844.

Programa de Pós-Graduação em Geoquímica Ambiental da Universidade Federal Fluminense. PPGG/ UFF (2020). Sobre o Programa. Niterói, RJ, UFF. URL: https://www.geoquimica-uff.com.br/index.php/apresentacao/sobre-o-programa. Acesso 08.05.2020.

Prigol, S., Giannotti, S. M. (2008). A importância da utilização de práticas no processo de ensino-aprendizagem de ciências naturais enfocando a morfologia da flor. In: Simpósio Nacional de Educação. Unioeste, Cascavel. URL: https://midas.unioeste.br/sgev/eventos/visimposionacionaldeeducacao/anais. Acesso 10.05.2020.

Rohde, G. M. (2013). Geoquímica Ambiental e Estudos de Impacto. 4 ed. São Paulo: Oficina de Textos. 160p.

Santos, M. (2004). Por uma geografia nova: da crítica à geografia a uma geografia crítica. 6 ed. São Paulo: EDUSP. 288p.

Santos, M. C. P., Bezerra, H. P. A., Firmino, A. R. S., Rodrigues, A. P. C., \& Rangel, J. (2013). O incentivo das aulas de campo no ensino de Geociências. Revista Eletrônica Novo Enfoque, 17(17), 94-99.

Santos, V. M. N. dos, \& Compiani, M. (2009). Formação de professores para o estudo do ambiente: projetos escolares e a realidade socioambiental local. Terrce Didatica, 5(1), 72-86. doi: 10.20396/ td.v5i1.8637506

Schenini, F. (2020). Interdisciplinaridade cresce na pós- graduação brasileira. Brasília, DF, Ministério da Educação (MEC). URL: http://portal.mec.gov. br/pec-g/180-discentes-108009469/pos-graduacao-500454045/6713-sp-1646083365. Acesso 10.05.2020.

Silva, J. S. R. da, Silva, M. B., \&Varejão, J. L. (2010). Os (des)caminhos da educação: a importância do trabalho de campo na geografia. Vértices, 12(3), 187-197.

Silva, M. A. S., Soares, I. R., Alves, F. C., \& Santos, M. N. B. (2012). Utilização de Recursos Didáticos no processo de ensino e aprendizagem de Ciências Naturais em turmas de $8^{\circ}$ e $9^{\circ}$ anos de uma Escola Pública de Teresina no Piauí. In: Congresso Norte-Nordeste de Pes-

\begin{tabular}{c|c|c|c|c|c|}
\hline (C) Terrae Didat. & Campinas, SP & v.16 & $1-12$ & $\mathrm{e} 020048$ & 2020 \\
\hline
\end{tabular}


quisa e Inovação (Connepi 7). Palmas, TO. URL: http://propi.ifto.edu.br/ocs/index.php/connepi/vii/ paper/viewFile/3849/2734. Acesso 10.05.2015.

Souza, C. C., Suzuki, K. N., Latini, R. M., Canesin, F., \& Bellido, A. V. B. (2017). Adsorção de metais em Biocarvão utilizando radiotraçadores para fins de remediação. In: XVI Congresso Brasileiro de Geoquímica. Armação de Búzios. URL: https://3313f8a2d231-43bd-be73-41e5429b57b2.filesusr.com/ugd/ 33bad3_92679fdca33642eca44489d5e9fb2f98.pdf. Acesso: 13.06 .2020$.
Teixeira, W., Fairchild, T. R., Toledo, M. C. M., \& Taioli, F. (2009). Decifrando a Terra. São Paulo: Companhia Editora Nacional. 621p.

Templeton, D. M., Ariese, F., Cornelis, R., Danielsson, L. -G., Muntau, H., Van Leeuwen, H. P., \& Łobiński, R. (2000). Guidelines for terms related to chemical speciation and fractionation of elements. Definitions, structural aspects, and methodological approaches (IUPAC Recommendations 2000). Pure and Applied Chemistry, 72(8), 1453-1470. 